\title{
DESCONTAMINACIÓN DE AGUAS Y LODOS USANDO ENZIMAS Y BACTERIAS: EVALUACIÓN DE TRES PRODUCTOS BIORREMEDIADORES PARTE 1: USO DE PROCESOS AEROBIOS
}

\author{
DECONTAMINATION OF WATER AND SLUDGE USING ENZYMES AND \\ BACTERIA: EVALUATION OF THREE BIOREMEDIATION PRODUCTS \\ PART 1: USE OF AEROBIC PROCESSES
}

\author{
JORGE E. CEVALLOS ROMERO', J. ESTEBAN CEVALLOS SALAZAR ${ }^{2}$
}

1 Universidad Católica de Santiago de Guayaquil. cevallos_jorge@hotmail.com

2 Universidad Estatal de la provincia de Santa Elena. instructor12345@icloud.com

Esta primera parte de la investigación evaluó tres productos comerciales constituidos por enzimas y bacterias que --conforme protocolos de aplicación, ensayos y parámetros de calidad, especificados y llevados a cabo bajo la guía de las compañías oferentes-- lograrían descontaminar, aplicando procesos aerobios, aguas y lodos de un sitio donde se descargan aguas lluvias y residuales, domésticas e industriales crudas. Se usaron cuatro reactores de cuarenta litros cada uno, donde se colocó igual cantidad de lodos y agua contaminada procedente de la misma fuente, para analizar si habría mejoras en su calidad ambiental. Todos los reactores arrancaron bajo las mismas condiciones y las dosificaciones de los biorremediadores la realizaron los oferentes conforme sus propios protocolos. Un reactor se usó como testigo, donde no se añadió producto alguno. Los otros tres sirvieron para evaluar separadamente cada uno de los productos comerciales mencionados. Se efectuaron separadamente análisis de la calidad ambiental inicial de sus lodos y agua, y luego cada diez días a lo largo de cincuenta días, comparando los resultados entre el testigo y los reactores donde se añadieron los productos comerciales. El reactor testigo produjo mejores resultados. Dos de los tres productos comerciales no cumplieron lo ofrecido por sus oferentes e inclusive deterioraron más la calidad ambiental del agua y lodos. Sólo uno de los productos comerciales arrojó resultados algo similares al del reactor testigo; sin embargo, al comparar entre ambos los ensayos de olores de los lodos contaminados del fondo, se encontró que el testigo presentaba menor mal olor.

PALABRAS CLAVE: enzimas, bacterias, biorremediación, olores, lodos, aguas residuales.
ABSTRACT

This first part of this research evaluated three commercial products containing enzymes and bacteria which --according to protocols of their use, applications, essays, and quality parameters specified and performed under the guidance of the offering companies-- would decontaminate, using aerobic processes, water and sludge polluted with domestic and industrial residues. Four reactors, 40-liter each, were used with the same amount of polluted sludge and water, obtained from the same source, to analyze if there was any improvement in environmental quality. All reactors started under the same conditions and the bioremediation products were applied as stated according to the commercial firms' established protocols. One reactor was used as a control with no bioremediation product in it. The other three reactors were evaluated separately with the previously mentioned commercial products. The initial environmental quality for the water and sludge was evaluated; then samples were withdrawn and analyzed each ten days throughout fifty days and the results were compared between the control and the reactors with the added commercial products. The control reactor gave the best results. Two of the three commercial products could not comply with what was stated by the offering firms and even deteriorated more the environmental quality of the water and the sludge. Only one of the commercial products gave results to some extent similar to the control reactor; however, when comparing the odor essays of the contaminated sludge from the bottom --of these two reactors-- it was found that the control had a lesser offensive odor.

KEYWORDS: enzymes, bacterias, bioremediation, odor, sludge, wastewater. 
INTRODUCCIÓN

El tema ambiental es quizá uno de los que más interés ha despertado últimamente en los círculos académicos y científicos a nivel mundial, debido a la creciente contaminación del agua, el suelo y el aire. La biorremediación y el uso de biopromotores es una tecnología comprobada que ofrece excelentes resultados cuando se la conoce y usa apropiadamente. En ella se utilizan organismos vivos (plantas, algas, hongos, bacterias y enzimas) para absorber, degradar o transformar los contaminantes y retirarlos, inactivarlos o atenuar su efecto en el suelo, el agua y el aire. Por tanto, se puede utilizar para limpiar terrenos y aguas contaminadas (Glazer y Nikaido, 1995).

\section{MARCO TEÓRICO}

La biorremediación ha sido exitosamente usada en muchos campos relacionados con la descontaminación, incluyendo pesticidas (Naofumi, 2013), aguas residuales complejas (Gaikwad, Wate, Ramteke \& Roychoudhury, 2014), aguas del molino de olivas usando levaduras (Bevilacqua, Petruzzi, Corbo \& Sinigaglia, 2013), aguas contaminadas con metales pesados usando semillas de Moringa Oleifera, (Araújo, Carvalho, Rezende, Almeida, Coelho, Marques, \& Alves, 2013), remoción de cromo hexavalente de soluciones y sitios contaminados usando diferentes biomasas naturales (Acosta-Rodríguez, Cárdenas-Conzález, Moctezuma-Zárate y Martínez-Juárez, 2013), así como nutrientes y materia orgánica, entre otros (Lavrova and Koumanova, 2013). Uno de los más recientes intereses en la ciencia tiene relación con la biología molecular, en particular la ingeniería genética, como herramienta para estudiar los mecanismos envueltos en la regulación de las transformaciones hacia cierta mineralización que se desea lograr (Ranjith y Pratap, 2013).

Elekwachi, Andresen, \& Hodgman (2014) evaluaron las tecnologías frecuentemente usadas alrededor del globo para encarar problemas ambientales. Recibieron respuestas de casi todos los continentes, y encontraron que, en muchos países, a pesar del interés en aplicar técnicas de biorremediación, ésta no era la práctica común. Hallaron también que existe una directa asociación en los habitantes entre ingresos per cápita y su preocupación sobre el ambiente, así como el que la contaminación de aguas subterráneas tiene mayor prioridad en regiones y/o países desarrollados. También hallaron que entre el 15 y el 35\% de los encues- tados usaron bases de datos en línea para guiar el diseño de sus experimentos, y que estos se usaban principalmente en Norteamérica y Europa. En Estados Unidos, las tres cuartas partes de los encuestados usaban programas de modelación versus un tercio en otros sitios. Consecuentemente, mientras en las economías desarrolladas hicieron alto uso de tecnologías de biorremediación de bajo costo in situ, los países en vías de desarrollo usaban tecnologías más caras, las cuales en ocasiones eran exsitu.

Se denomina biorremediación intrínseca o atenuación natural, a la que se lleva a cabo por los microorganismos autóctonos, principalmente bacterias del medio afectado (Rosenberg y Ron, 1996). Estos pueden llevarse a cabo bajo diversas condiciones aerobias, anóxicas, o anaerobias, o con una combinación de ambas.

Este tipo de biorremediación natural es el que mayormente se emplea para las aguas residuales domésticas y para las aguas residuales industriales orgánicas, y no la aplicación de organismos externos.

Lamentablemente en algunos países en vías de desarrollo, representantes de firmas comercializadoras internacionales están ofreciendo productos biorremediadores con los cuales, por desconocimiento al aplicarlos, hacen mal uso de principios técnicos y científicos, resultando en aparatosos fracasos para los clientes. La ignorancia de elementales principios de biorremediación y sus limitantes han llevado a su uso, aún por parte de autoridades de control ambiental, con deficientes o dudosos resultados que no se publican.

OBJETIVO

Evaluar los resultados de aplicar tres productos que se venden en la ciudad de Guayaquil como biorremediadores y/o biopromotores, constituidos -según sus comercializadores- por enzimas y bacterias que lograrían descontaminar aguas y lodos de sitios donde descargan aguas lluvias y aguas residuales domésticas e industriales no tratadas.

Los ensayos se realizaron conforme protocolos de uso, aplicación y parámetros a medirse, especificados y llevados a cabo bajo la dosificación y guía de los mismos oferentes de tales productos comerciales. Los análisis químicos y biológicos a lo largo de cincuenta días mostraron que dos de los tres productos contaminaron más el agua y los lodos. El tercer producto dio resultados químicos, algo parecido al del testigo, excepto que empeoró el olor de los lodos del fondo. 


\section{HIPÓTESIS}

El empleo de enzimas y bacterias es útil -dentro de ciertos límites- en la descontaminación de algunos residuos. Lamentablemente en nuestro medio hay desconocimiento de tales limitantes por parte de sus comercializadores y de algunas autoridades ambientales. Como resultado, en algunos casos, se produce la pérdida de tiempo y dinero para quienes solicitan y usan tales servicios.

MATERIALES Y MÉTODOS

Se llevaron los ensayos bajo condiciones de control en el local de un laboratorio acreditado, seleccionado por los oferentes de los biorremediadores y biopromotores. Se usaron cuatro envases idénticos de plástico traslúcido con capacidad neta de cuarenta litros cada uno. Se colocó en cada uno de ellos la misma calidad y cantidad de agua y lodos contaminados. Luego se tomaron muestras iniciales de su calidad, antes de colocar producto alguno en los reactores, para comparar futuros cambios. Por lo anotado, los oferentes de los biorremediadores y bio-promotores tenían conocimiento cabal de la calidad del agua y lodos que iban a tratar con sus productos, y en base a ello cada uno escogió su estrategia de dosificación y aplicación.

Se enfatiza que se trata de productos cuyos comerciantes o distribuidores dicen estar elaborados a base de enzimas y bacterias que supuestamente eliminan la contaminación y los malos olores de aguas y lodos si se siguen las indicaciones de los fabricantes. Como es lógico y natural, los oferentes no entregaron la formulación exacta que contienen sus productos por ser marca registrada. Se utilizó uno de los reactores como testigo o blanco (reactor T). En los otros tres se dosificaron, separadamente, cada uno de los biorremediadores a investigar que, para propósitos de este artículo, se mencionan como A, B, y C.

Los procedimientos específicos, que se siguieron conforme lo especificó cada oferente, fueron:

- Reactor T: correspondió al testigo. No se colocó biorremediador alguno.

- Reactor A: Los procedimientos que se usaron para el Reactor A se presentan en las Tablas 1, 2 y 3, conforme a lo especificado por los oferentes.
TABLA 1. PROCEDIMIENTO ESPECÍfICO DE APLICACIÓN EN EL REACTOR A

\begin{tabular}{ll}
\hline 1 & $\begin{array}{l}\text { Tomar agua para ser vertida en los dos recipientes, tanto } \\
\text { tratamiento como testigo. }\end{array}$ \\
\hline 2 & $\begin{array}{l}\text { Una vez realizado el paso } 1 \text { proceder a la toma de muestra y } \\
\text { realizar análisis del agua, la cual será la misma línea base para } \\
\text { el tratamiento como para el testigo, esto se le realizará antes del } \\
\text { tratamiento. }\end{array}$ \\
\hline 3 & $\begin{array}{l}\text { Verter el agua de la misma fuente para el tratamiento y testigo } \\
\text { en partes iguales, en } 20 \text { litros cada uno, antes de dividir el agua } \\
\text { hacer análisis. }\end{array}$ \\
\hline 4 & $\begin{array}{l}\text { Iniciar la distribución del aire. } \\
\text { Coordinar el encendido de la luz por } 14 \text { horas }\end{array}$ \\
\hline 6 & $\begin{array}{l}\text { Aplicar bio-promotores sólo en el reactor de tratamiento bajo el } \\
\text { esquema planteado. }\end{array}$ \\
7 & $\begin{array}{l}\text { Tomas de muestras de agua para analizar parámetros y describir } \\
\text { tendencia de eficiencia. }\end{array}$ \\
\hline
\end{tabular}

Nota: Especificaciones de los oferentes de los productos comerciales utilizados.

\section{TABLA 2. PREPARACIÓN DE DOSIS POR APLICACIÓN EN REACTOR A}

Pesar 10 gr del biopromotor

Luego de pesado diluir en $1 \mathrm{~L}$ de agua pura

De la dilución tomar $3 \mathrm{cc}$ de la mezcla para 20 litros de agua.

Aplicar el producto en el tratamiento

Nota: Especificaciones de los oferentes de los productos comerciales utilizados.

TABLA 3. ESQUEMA DE DOSIFICACIÓN PARA LA REDUCCIÓN DE ALGAS PLANCTÓNICAS EN REACTOR A

\begin{tabular}{ll}
\hline $\begin{array}{l}\text { DURACIÓN DE LA APLICACIÓN } \\
\text { NÚMERO DE APLICACIONES }\end{array}$ & Sólo 15 días \\
FRECUENCIA DE APLICACIÓN & Cada 2 días \\
\hline $\begin{array}{l}\text { DOSIS POR APLICACIÓN } \\
\text { FRECUENCIA DE ANÁLISIS }\end{array}$ & 0,03 gr en 20 litros \\
\hline $\begin{array}{l}\text { PARÁMETROS A ANALIZAR } \\
\text { (PARA EL TRATAMIENTO Y } \\
\text { TESTIGO) }\end{array}$ & $\begin{array}{l}\text { Clorofila, } \\
\text { Cantidad de células de alga verde }\end{array}$ \\
& $\begin{array}{l}\text { Transparencia del agua, turbiedad y } \\
\text { parámetros que se consideren pertinentes }\end{array}$ \\
\hline
\end{tabular}

REACTOR B

Para este reactor su dosificación fue muy sencilla y se siguieron las directrices de los oferentes. El arranque fue de 20 gramos; a continuación 3 gramos diarios en los siguientes días. Se colocó el sedimento en el reactor, luego se procedió a asperjar sobre él 9,5 mL de organismos eficaces (OE) se dejó actuar por dos horas, y luego fue agregada el agua contaminada del Estero Salado. Esta fue la única aplicación para el lodo. 
REACTOR C

Caso de los organismos eficaces (OE). Para el reactor del laboratorio se colocó el lodo en el fondo. Se aplicaron $40 \mathrm{~mL}$ de OE sobre el lodo por cada 5 $\mathrm{cm}$ de profundidad de lodos. Luego se completó el reactor con $10 \mathrm{~cm}$ de altura usando agua del estero contaminado, y finalmente $40 \mathrm{~mL}$ de $\mathrm{OE}$.

Dosificación de OE en sedimentos y agua: el primer día se aplicaron $40 \mathrm{~mL}$ de OE al lodo y luego ese mismo día se aplicaron $40 \mathrm{~mL}$ al agua que va encima de los lodos. Durante las semanas 1 y 2 se realizaron aplicaciones diarias de $40 \mathrm{~mL}$, para un total de 7 aplicaciones cada semana. Desde la semana 3 hasta la semana 6 , se realizaron tres aplicaciones semanales, lunes, miércoles y viernes de $40 \mathrm{~mL}$ c/u. El primer día se aplicaron organismos eficaces tipo b (OE-b) al sedimento como parte del tratamiento. En la Tabla 4 se resumen las dosificaciones propuestas por los oferentes de este producto.

\begin{tabular}{|c|c|c|c|c|c|c|}
\hline $\begin{array}{l}\text { ACTIVIDADES / } \\
\text { SEMANAS }\end{array}$ & 1 & 2 & 3 & 4 & 5 & 6 \\
\hline $\begin{array}{l}\text { FRECUENCIA DE } \\
\text { APLICACIONES DE (OE) }\end{array}$ & 7 & 7 & 3 & 3 & 3 & 3 \\
\hline $\begin{array}{l}\text { TOTAL A APLICARSE } \\
\text { POR SEMANA }\end{array}$ & 320 & 280 & 120 & 120 & 120 & 120 \\
\hline DOSIS DE (OE) DIARIAS & \multicolumn{6}{|c|}{40 mL por aplicación } \\
\hline APLICAR OE-B & 1 & & & & & \\
\hline
\end{tabular}

Nota: Especificaciones de los oferentes de los productos comerciales utilizados.

Los cuatro reactores se mantuvieron operando bajo similares condiciones de luz, temperatura y oxígeno disuelto, pero en el testigo jamás se añadieron los biorremediadores. Los protocolos y criterios sobre las frecuencias de aplicaciones y concentraciones de los productos comerciales (biorremediadores A, B y C) en las muestras de aguas y lodos fueron establecidos por los oferentes de tales productos de forma independiente. Fueron llevadas a cabo por el laboratorio contratado por ellos.

Cada diez días el personal del laboratorio tomaba muestras de aguas y lodos de los reactores para conocer si los biorremediadores estaban mejorando la calidad de los mismos. El tiempo total de la experimentación, hasta que se reportaron los resultados, fue de cincuenta días. Los oferentes argumentaron que era suficiente para obtener conclusiones válidas.

\section{PARÁMETROS FÍ́ICOS/QUÍMICO Y BIOLÓGICOS EN AGUA Y LODOS}

La lista de parámetros investigados a remediar tanto en lodos como en aguas conforme a la solicitud de los oferentes de los productos comerciales, se presentan en la Tabla 5. Los ensayos siguieron los procedimientos de Standard Methods, American Public Health Association (APHA), American Water Works Association (AWWA) y Water Environment Federation (WEF).

TABLA 5. LISTA DE PARÁMETROS DE CALIDAD AMBIENTAL
ANALIZADOS EN AGUA Y EN LODOS, CONFORME LO SOLICITARON
LOS OFERENTES DE LOS PRODUCTOS BIORREMEDIADORES PUESTOS
A PRUEBA
\begin{tabular}{ll}
\hline MEDICIONES EN AGUA & MEDICIONES EN LODOS \\
\hline Azufre, \% & Sulfuro de hidrógeno, $\mathrm{mg} / \mathrm{Kg}$ \\
\hline Coliformes fecales, NMP/100 $\mathrm{mL}$ & Materia Orgánica, $\mathrm{g} \%$ \\
\hline Nitrógeno total, $\mathrm{mg} / \mathrm{L}$ & Potencial Redox, $\mathrm{mV}$ \\
\hline Potencial de hidrógeno & Alcalinidad, como CaCO ${ }_{3}, \mathrm{mg} / \mathrm{L}$ \\
\hline Turbidez, (UTN) & Fosfatos, $\mathrm{mg} / \mathrm{L}$ \\
\hline DQ0, $\mathrm{mg} / \mathrm{L}$ & Percepción de Olores \\
\hline
\end{tabular}

ENSAYOS DE OLORES

Los ensayos de olores de los lodos que se encontraban en el fondo de los reactores aerobios también se realizaron conforme Standard Methods, en muestras tomadas al término de los cincuenta días. Personal del laboratorio contratado por los mismos oferentes usó lodo extraído del fondo del reactor que arrojó los mejores resultados químicos y biológicos (Producto A). Los vendedores de los otros dos productos decidieron no participar debido al deterioro que ocurrió en sus aguas y lodos. Se colocó el lodo del reactor aerobio mencionado en juegos de botellas separadas en las siguientes cantidades: $1 \mathrm{~g} / \mathrm{botella}$; $5 \mathrm{~g} /$ botella; $10 \mathrm{~g} /$ botella, por duplicado. Similar procedimiento se realizó con el lodo del reactor que servía como testigo o blanco. También se colocó entre las botellas un par que no contenían lodos. Se envolvió cada botella con papel aluminio que impedía conocer su contenido y se colocó en su parte externa un código, sólo conocido por el personal del laboratorio, que identificaba el contenido y concentración dentro de cada una de las botellas. El código se mantuvo en sobre cerrado y fue revelado luego de completar los ensayos.

Se escogió a un grupo de ocho técnicos para que conformen el panel de identificación de olores, usando las normas estándares para tales procedimientos. Se les hizo conocer con antelación que entre las botellas habría algunas con 
lodos malolientes. Se les solicitó identificar la intensidad del olor de las diversas botellas tomadas secuencialmente una por una al azar.

Se hicieron dos rondas de identificación de olores, con el objetivo de aumentar las condiciones de selección al azar de las botellas por parte de los panelistas y comprobar la consistencia de los resultados. Se cumplieron todos los procedimientos técnicos y éticos aceptados para este tipo de ensayos. Los delegados de las empresas que venden esos biorremediadores en todo momento tuvieron acceso a los procedimientos aplicados por el laboratorio, para que pudiesen comprobar los resultados.

Los panelistas tenían que dar un puntaje entre 0 y 3 al olor de las botellas, debiendo ser más alto para las botellas donde percibían un mal olor más intenso, y más bajo donde era menor o ninguno. Por lo tanto, la mayor percepción de contaminación de malos olores generaría una curva donde los puntos más elevados corresponderían a aquellas botellas donde se lo percibía en mayor grado.

\section{RESULTADOS Y DISCUSIÓN}

Los resultados, bajo procesos aerobios, se obtuvieron para: (a) variación en la calidad de las aguas; (b) variación en la calidad ambiental de sus lodos del fondo que, además, incluyó la medición de la intensidad del olor de esos lodos.

El oferente del Producto $C$ abandonó los ensayos aerobios antes de cumplir los veinte días pues, por el deterioro en la calidad de su agua, decidió cambiar a un proceso anaerobio. Por esa razón no se han graficado sus únicos resultados aerobios a los diez días, habiéndose dejado los resultados posteriormente obtenidos bajo condiciones anaerobias para un futuro artículo científico.

En el reactor del testigo, como en aquellos donde se aplicaron los productos A y B, se observaron las variaciones en la calidad del agua a lo largo de cincuenta días, tomando muestras cada diez días. Se presentan a continuación las Tablas 6 y 7 con los promedios y desviación estándar (Desv. Est.) de los resultados de la calidad ambiental en el agua y lodos, respectivamente:

Conforme muestran las Tablas 6 y 7 algunos resultados del testigo, en ocasiones fueron mejores que los del Producto A, pero en otras resultó lo contrario. Sin embargo, para propósitos prácticos, los rangos de diferencia no son tan marcados como los que se observaron al comparar al testigo $(\mathrm{T})$ con el reactor donde se dosificó el Producto B.
TABLA 6. RESULTADOS DE LA CALIDAD AMBIENTAL DEL AGUA. SE COMPARA EL TESTIGO CON LOS PRODUCTOS BIORREMEDIADORES/ BIO-PROMOTORES

\begin{tabular}{lcrrr}
\hline $\begin{array}{l}\text { PARÁMETROS } \\
\text { AMBIENTALES }\end{array}$ & $\begin{array}{c}\text { PARÁMETRO } \\
\text { ESTAD́́stico }\end{array}$ & TESTIGO (T) & PRODUCTO A & PRODUCTO B \\
\hline \multirow{2}{*}{ PH } & Promedio & 8,26 & 8.59 & 7.14 \\
& Desv. Est. & 0.30 & 0.22 & 1.41 \\
\hline \multirow{2}{*}{ DQO (MG/L) } & Promedio & 39.42 & 27.34 & 1659.49 \\
& Desv. Est. & 26.26 & 18.53 & 1461.37 \\
\hline N TOTAL & Promedio & 7.83 & 8.79 & 32.47 \\
(MG/L) & Desv. Est. & 4.07 & 2.05 & 33.99 \\
\hline \multirow{2}{*}{ TURBIEDAD } & Promedio & 3.05 & 2.04 & 250.78 \\
\hline & Desv. Est. & 3.82 & 1.94 & 169.22 \\
\hline COLI FECALES & Promedio & 30.50 & 109.00 & 444.75 \\
(NMP/100 ML) & Desv. Est. & 81.09 & 82.18 & 837.22 \\
\hline \multirow{2}{*}{ AZUFRE (\%) } & Promedio & 0.04 & 0.04 & 0.02 \\
\hline & Desv. Est. & 0.02 & 0.02 & 0.02 \\
\hline
\end{tabular}

Nota: Datos proporcionados por el laboratorio acreditado para la realización de los ensayos.

TABLA 7. RESULTADOS DE LA CALIDAD AMBIENTAL DEL LODO. SE COMPARA EL TESTIGO CON LOS PRODUCTOS BIORREMEDIADORES/ BIOPROMOTORES

\begin{tabular}{|c|c|c|c|c|}
\hline $\begin{array}{l}\text { PARÁMETROS } \\
\text { AMBIENTALES }\end{array}$ & $\begin{array}{l}\text { PARÁMETRO } \\
\text { ESTADÍSTICO }\end{array}$ & TESTIGO (T) & PRODUCTO A & PRODUCTO B \\
\hline \multirow{2}{*}{$\begin{array}{l}\text { SULFURO DE } \\
\text { HIDRÓGENO, } \\
\text { (MG/KG) }\end{array}$} & Promedio & 0.22 & 0.15 & 0.24 \\
\hline & Desv. Est. & 0.13 & 0.14 & 0.20 \\
\hline \multirow{2}{*}{$\begin{array}{l}\text { MATERIA } \\
\text { ORGÁNICA, } \\
(G, \%)\end{array}$} & Promedio & 20.54 & 16.40 & 17.55 \\
\hline & Desv. Est. & 3.76 & 2.03 & 1.04 \\
\hline \multirow{2}{*}{$\begin{array}{l}\text { POTENCIAL } \\
\text { REDOX, (MV) }\end{array}$} & Promedio & -84.05 & -120.00 & -93.78 \\
\hline & Desv. Est. & 25.05 & 12.73 & 31.76 \\
\hline \multirow{2}{*}{$\begin{array}{l}\text { ALCALINIDAD, } \\
\text { COMO CACO }_{3} \text {, } \\
\text { MG/L }\end{array}$} & Promedio & 582.55 & 588.50 & 1100.00 \\
\hline & Desv. Est. & 238.14 & 198.31 & 562.32 \\
\hline \multirow{2}{*}{$\begin{array}{l}\text { FOSFATOS, } \\
\text { (MG/L) }\end{array}$} & Promedio & 4.25 & 3.48 & 61.65 \\
\hline & Desv. Est. & 2.22 & 0.50 & 57.68 \\
\hline \multirow{2}{*}{ AZUFRE, (\%) } & Promedio & 0.04 & 0.04 & 0.02 \\
\hline & Desv. Est. & 0.023 & 0.025 & 0.021 \\
\hline
\end{tabular}

Nota: Datos proporcionados por el laboratorio acreditado para la realización de los ensayos.

En las Figuras 1 a la 10 que muestran los resultados del testigo, tanto en sus puntos de concentración más alta y más baja, se trazó una línea horizontal punteada que abarca a manera de envolvente al resto de resultados. Esto facilita la comparación con los reactores donde se dosificaron los biorremediadores. Debajo de las 
figuras se encuentran los rangos de resultados en el reactor $\mathrm{T}$ (testigo o blanco) y en los que se dosificaron los biorremediadores A y B.

La calidad del reactor testigo, como es natural, varió algo a lo largo de los cincuenta días pues el agua y lodos colocados en él ya contenían contaminación física, química y biológica del sitio muestreado. Por lo tanto, la biota que naturalmente existía y demás compuestos, sufrirían algún grado de alteraciones con el tiempo. Similar evento ocurrió en los tanques donde se dosificaron los biorremediadores.

Lo importante de estos ensayos es comparar esos rangos de variación con los del testigo. Si los resultados para los productos comerciales cayeran dentro de las líneas paralelas horizontales del testigo y fueran similares o muy cercanos a los mismos, significaría que no hay una variación digna de tomarse en cuenta. Por lo tanto, los biorremediadores comerciales no habrían influido ni de manera positiva ni negativa. Si los resultados de los productos comerciales estuvieran encima o debajo de los del testigo, significarían resultados favorables o desfavorables, según el parámetro medido.

\section{(A) PROCESO AEROBIO: RESULTADOS DE LOS PARÁMETROS MEDIDOS EN EL AGUA}

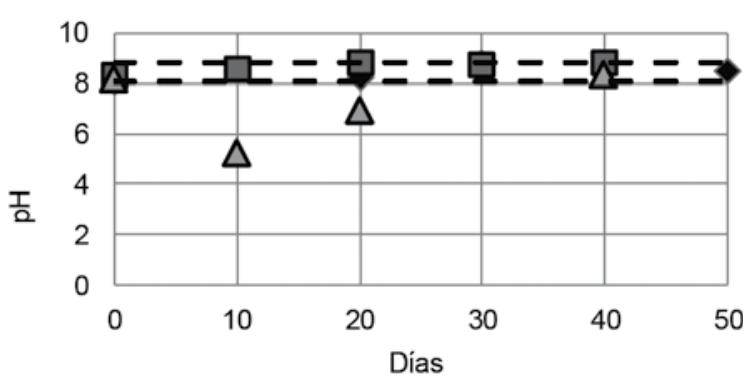

$\bullet T: 8.03-8.83 \square A: 8.32-8.86 \Delta$ B: $5.23-8.30$

Figura 1. El pH del testigo y del producto A no varió mucho. Los resultados del producto $B$ en dos ocasiones estuvieron debajo de la envolvente del testigo que se muestra como dos líneas paralelas punteadas, lo que revela una indeseable acidificación inicial que varió de 5.23 a 8.30 .

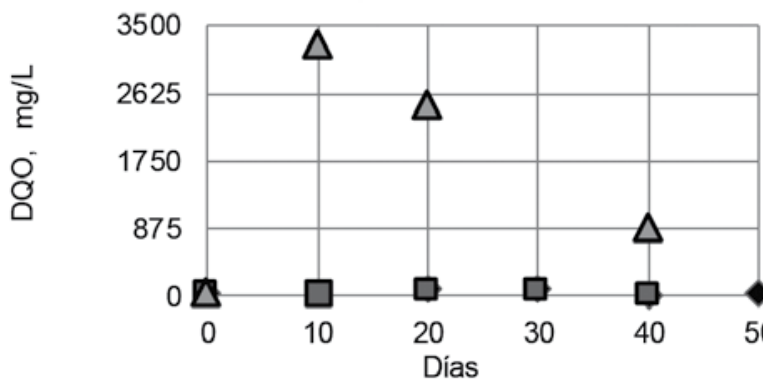

•T: 19.80 - 88.00 口A: 15.84 - $64 \Delta$ B: 38.83 - 3240

Figura 2. Con el Producto B en tres ocasiones la Demanda Química de Oxígeno (DQO) estuvo muy por encima de los resultados del testigo.

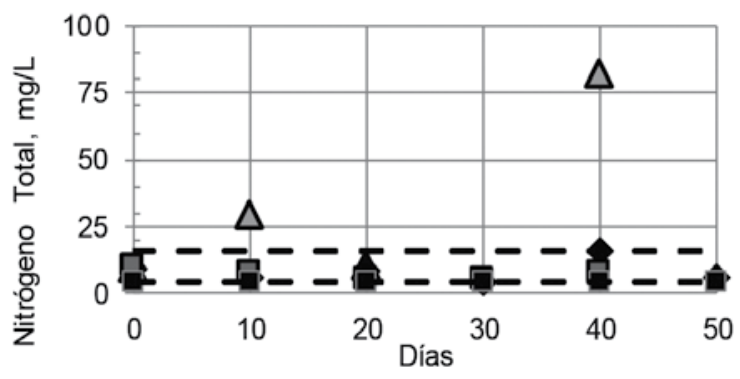

•T: 4.30 - 15.64 口A: $5.00-10.00 \Delta$ B: $9.40-81.59$

Figura 3. Con el Producto $B$ en dos ocasiones el nitrógeno total estuvo encima de la envolvente y fuera de la norma nacional, lo cual es un efecto negativo. En los otros casos los resultados estuvieron muy cercanos.

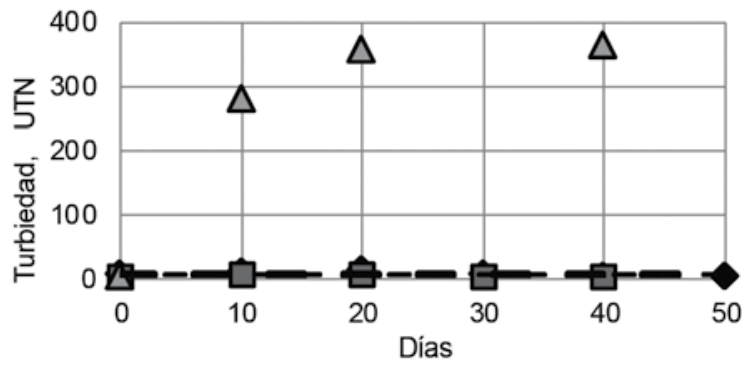

$\bullet \mathrm{T}=0.78-10.60 \square \mathrm{A}: 0.97-6.10 \Delta \mathrm{B}: 3.10-362$

Figura 4. La turbiedad (un efecto negativo) que generó el producto $B$ estuvo bastante por encima de los valores del testigo.

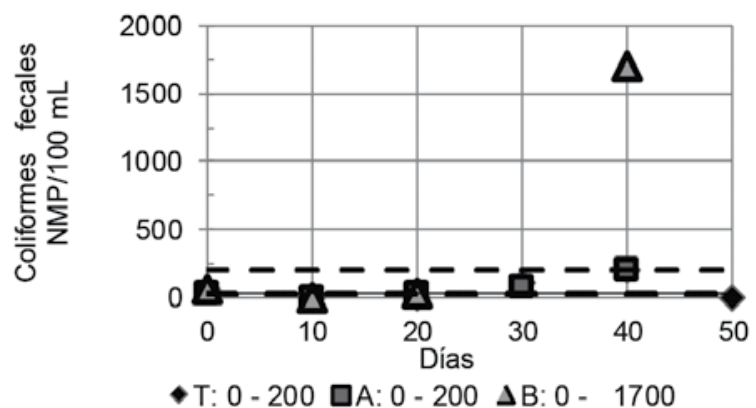

Figura 5. Los coliformes fecales en el testigo y en el reactor A fueron similares variando entre 0 a 200. El reactor $B$ presentó una mayor concentración de coliformes fecales.

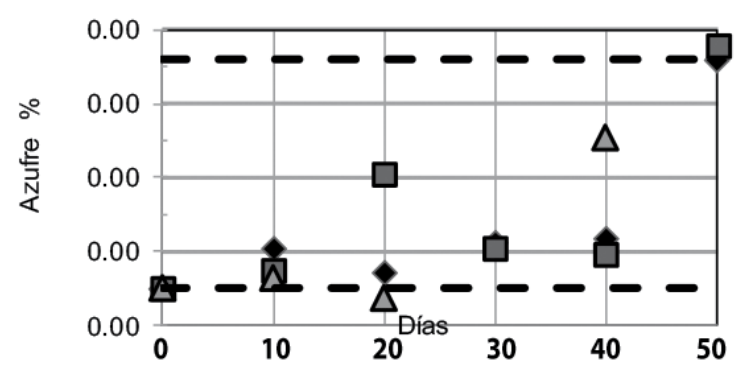

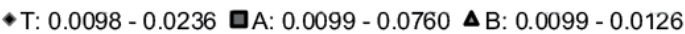

Figura 6. El porcentaje de azufre fue inicialmente similar. La variación no fue mayor comparado con el testigo. 
(B) PROCESO AEROBIO: RESULTADOS DE LOS PARÁMETROS MEDIDOS EN LOS LODOS

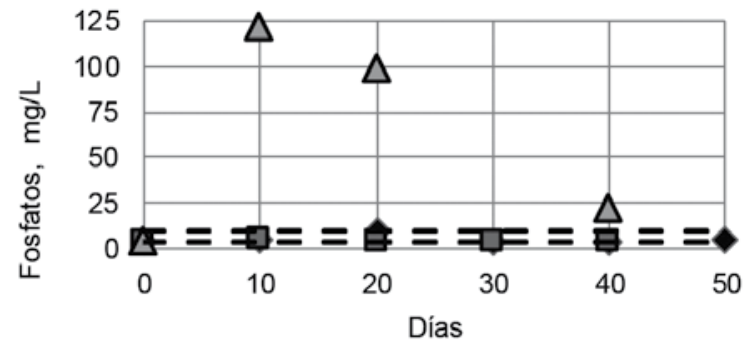

४ T: $3.06-9.20 \square \mathrm{A}: 3.20-3.58 \Delta \mathrm{B}: 3.58-122$

Figura 7. Para los fosfatos, el reactor B sobrepasó ampliamente los valores contaminantes máximos encontrados en el testigo. Los resultados del reactor $\mathrm{A}$ ( 3.20 a $3.58 \mathrm{mg} / \mathrm{L}$ ) estuvieron más cercanos que los valores del testigo que varió entre 3.06 y $9.20 \mathrm{mg} / \mathrm{L}$.

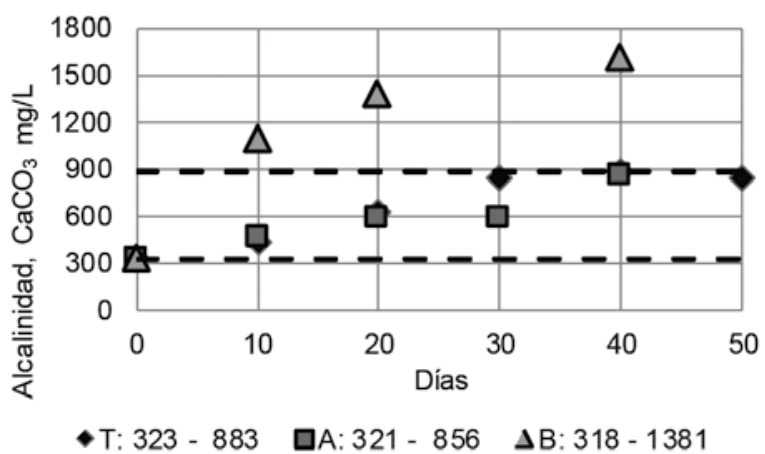

Figura 8. La alcalinidad en el testigo se mantuvo entre 323 y $883 \mathrm{mg} / \mathrm{L}$. En el reactor $B$ aumentó consistentemente su concentración a lo largo del tiempo, desde 318 hasta $1381 \mathrm{mg} / \mathrm{L}$.

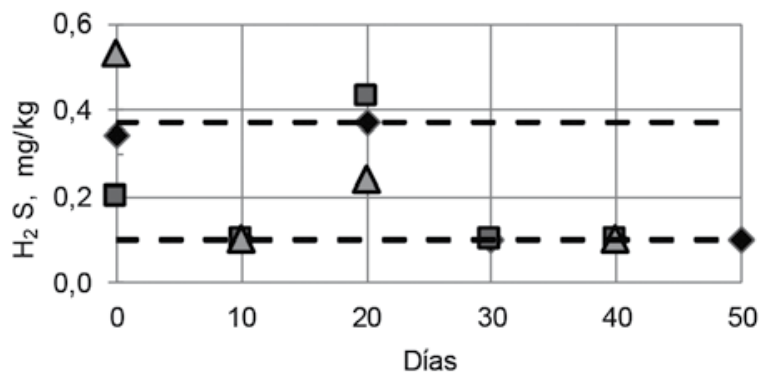

$\bullet$ T: $0.10-0.37 \square \mathrm{A}: 0.10-0.43 \Delta \mathrm{B}: 0.10-0.53$

Figura 9. El sulfuro de hidrógeno en la mayoría de los casos se mantuvo dentro del rango del testigo, pero en dos ocasiones presentaron una mayor acumulación.

En las Figuras 1 a la 10 se observó que el Producto A presentó rangos algo semejantes a los del testigo, donde ningún producto se añadió. El Producto B dio malos resultados. Sin embargo, su casa comercial se mantuvo hasta el día cincuenta cuando, debido al deterioro de sus aguas y lodos, decidió no continuar con la siguiente fase correspondiente a los ensayos de olores

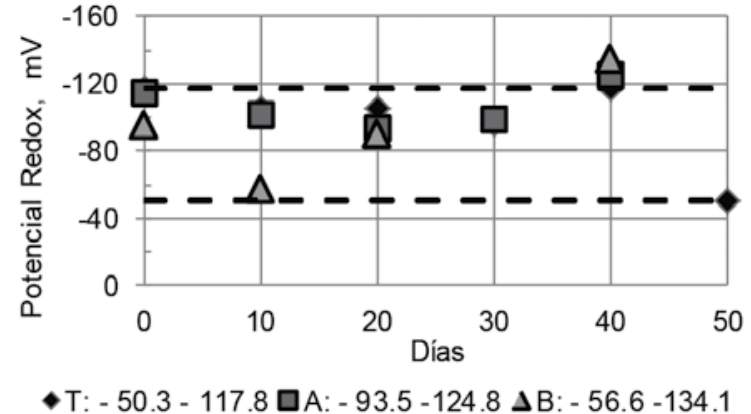

Figura 10. Para el potencial redox, los reactores A y B estuvieron fuera de la envolvente del testigo en una ocasión.

de sus lodos del fondo. Los ensayos de olores, presentados en el Figura 11, muestran que al comparar el olor del lodo del reactor testigo, con el del reactor donde se aplicó el Producto A, este último presentó consistentemente peor olor, expresado por su mayor puntaje en las botellas donde se colocó 1 , 5 y 10 gramos de lodos. Cuando la cantidad de muestra de lodos colocada en las botellas era cero gramos, coincidía la similar percepción de olores, como se observa al inicio de las dos curvas en la Figura 11.

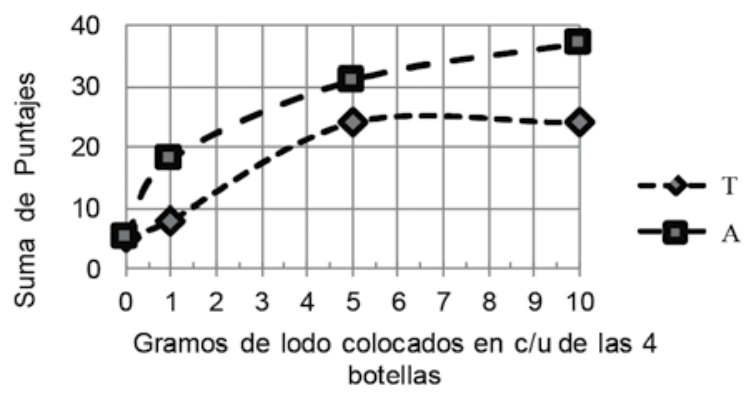

Figura 11. Resultado de ensayos de olores de los lodos bajo proceso aerobio. Los panelistas percibieron mayor mal olor en los lodos de las botellas donde se aplicó el Producto A, representado por una curva más alta. En las muestras que contenían el testigo (T) donde no se aplicó producto alguno, consistentemente percibieron menor mal olor.

Es necesario enfatizar que en las tuberías de aguas residuales y sitios donde se las descarga, ya viven los microorganismos que mejor se han adaptado a la contaminación, se alimentan de ella, y se reproducen en ese medio. Los seres humanos al ser omnívoros, sus aguas residuales contienen, para beneficio de los microorganismos, nutrientes, micronutrientes, restos de vitaminas, proteínas, aminoácidos, enzimas, etc.

El colocar organismos foráneos y enzimas sin adecuada evaluación previa integral por parte de los oferentes de biorremediadores y 
bio-promotores no sólo resultó innecesario sino hasta contraproducente. De hecho, el comercializador del producto que peores resultados arrojó, según se pudo conocer, fue el que decidió añadir mayor concentración de bacterias y enzimas extrañas al medio, lo cual posiblemente añadió mayor carga orgánica contaminante a su reactor. El comercializador del Producto A, usó ínfimas cantidades y logró mejores resultados que se asemejan -hasta cierto punto- a los del testigo, donde nada se añadió.

En cuanto a los olores, se compararon los resultados de los lodos del Producto A versus los del testigo al final de los cincuenta días. El vendedor del Producto $B$, prefirió no participar en los ensayos de olores por el grave deterioro en la calidad ambiental que sufrió su reactor. Sólo quedaron en pie para la última prueba, el testigo (T) y el Producto A.

La Figura 11 muestra el promedio de los resultados de los puntos asignados por los panelistas a las botellas que contenían el testigo (T) y el producto A, dando mayor puntaje a las botellas que presentaban un más intenso mal olor. Donde la cantidad de lodos contaminados, dentro de las botellas, era mayor también percibieron mayor olor. Sin embargo, se observará que en el testigo ( $\mathrm{T}$ ) la emisión de malos olores de su lodo-que no recibió tratamiento con enzimas ni bacterias-- fue consistentemente menor para todos los casos. Los valores menores, punteados en la curva del testigo (T) en la Figura 11, denotan mejores resultados.

CONCLUSIONES

El uso de los tres biorremediadores y biopromotores que contienen enzimas y bacterias, conforme lo especificaron sus fabricantes, no produjo mejoras significativas ni en la calidad de las aguas ni en la calidad de lodos contaminados con aguas residuales domésticas e industriales, al compararlos con los resultados obtenidos en el reactor control o testigo donde ningún producto se usó. Dos de los tres productos comerciales sólo empeoraron la situación. Hubo uno (Producto A) cuyos resultados físicos, químicos y biológicos se asemejaron a los del testigo. Sin embargo, al llevar a cabo los ensayos de olores, sus resultados fueron inferiores a los del testigo.

Se desea dejar en claro que los procesos de remediación trabajan muy bien siempre que se los use en determinadas circunstancias y condiciones especiales que deben técnicamente entenderse, conocerse, y aplicarse correctamente por verdaderos especialistas.
La comercialización de determinados productos ha llegado a proporciones serias en Ecuador debido al escaso conocimiento que tienen los vendedores sobre sus limitaciones. Es de esperar que las casas comerciales internacionales instruyan a sus representantes y vendedores en países como el nuestro, para que no extrapolen los usos de tales productos y conozcan sus limitaciones. De esa manera no perjudicará a desconocedores de la materia. Así también, deberán responsabilizarse por la pérdida de tiempo y dinero en que hacen incurrir a sus clientes, tanto particulares como a entidades del Estado.

\section{REFERENCIAS BIBLIOGRÁFICAS}

Acosta-Rodríguez, I., Cárdenas-González J. F., Moctezuma-Zárate, M.G \& MartínezJuárez, J. M., (2013). Removal of Hexavalent Chromium from Solutions and Contaminated Sites by Different Natural Biomasses, Applied Bioremediation - Active and Passive Approaches, Dr. Yogesh Patil (Ed.), InTech, 9, 209-229. doi: 10.5772/56152. Recuperado de: http://www.intechopen.com/books/appliedbioremediation-active-and-passive-approaches/ removal-of-hexavalent-chromium-fromsolutions-and-contaminated-sites-by-differentnatural-biomasses.

Araújo C. S. T., Carvalho, D. C., Rezende, H.C., Almeida I. L.S, Coelho, L. M.,, Coelho, N. M.M., Marques, T. L., \& Alves V., N. (2013). Bioremediation of Waters Contaminated with Heavy Metals Using Moringa oleifera Seeds as Biosorbent, Applied Bioremediation - Active and Passive Approaches, Dr. Yogesh Patil (Ed.), InTech, 10, 227-255. doiI: 10.5772/56157. Recuperado de: http://www.intechopen.com/ books/applied-bioremediation-active-andpassive-approaches/bioremediation-of-waterscontaminated-with-heavy-metals-usingmoringa-oleifera-seeds-as-biosorbent.

Bevilacqua, A., Petruzzi, L., Corbo M.R., and Sinigaglia, M., (2013). Bioremediation of Olive Mill Wastewater by Yeasts - A Review of the Criteria for the Selection of Promising Strains, Applied Bioremediation - Active and Passive Approaches, Dr. Yogesh Patil (Ed.), InTech, 3, 53-58. doi: 10.5772/56916. Recuperado de: http://www.intechopen.com/ books/applied-bioremediation-active-andpassive-approaches/bioremediation-of-olivemill-wastewater-by-yeasts-a-review-of-thecriteria-for-the-selection-of-prom. 
ElekwachiC.O., AndresenJ., HodgmanT.C., (2014) Clobal Use of Bioremediation Technologies for Decontamination of Ecosystems. J. Bioremediation \& Biodegradation 5-225. http://dx.doi.org/10.4172/2155-6199.1000225

Gaikwad G. L., Wate S. R., Ramteke D. S., Roychoudhury, K. (2014) Development of Microbial Consortia for the Effective Treatment of Complex Wastewater. J. Bioremediation \& Biodegradation, 5, 227. doi:10.4172/21556199.1000227.

Glazer N. A. y Nikaido (1995) Microbial Biotechnology: Fundamentals of Applied Technology. New York: W. H. Feeman Company.

Lavrova, S., and Koumanova, B. (2013). Nutrients and Organic Matter Removal in a Vertical-Flow Constructed Wetland, Applied Bioremediation - Active and Passive Approaches, Dr. Yogesh Patil(Ed.), InTech, 4, 69-99. doi: 10.5772/56245. Recuperado de: http://www.intechopen. com/books/applied-bioremediation-activeand-passive-approaches/nutrients-andorganic-matter-removal-in-a-vertical-flowconstructed-wetland.

Naofumi, S., (2013), A Novel Bioremediation Method for Shallow Layers of Soil Polluted by Pesticides. Department of Human Sciences, Kobe College, Hyogo, Japan. Dr. Yogesh Patil (Ed.), InTech, 12, 288-306. doi: 10.5772/56153. Recuperado de: http://www.intechopen.com/ books/applied-bioremediation-active-andpassive-approaches/a-novel-bioremediationmethod-for-shallow-layers-of-soil-polluted-bypesticides.
Ranjith N. K. and Pratap D. (2013). Scientific Swift in Bioremediation: An Overview, Applied Bioremediation - Active and Passive Approaches, Dr. Yogesh Patil (Ed.), InTech, 16, 377-396. doi: 10.5772/56409. Recuperado de: http://www.intechopen. com/books/applied-bioremediation-activeand-passive-approaches/scientific-swift-inbioremediation-an-overview.

Rosenberg, E. y Ron, E.Z. (1996). Bioremediation of petroleum contamination. In: Crawford RL \& Crawford DL (Eds) Bioremediation. Principles and Applications. Biotechnology Research Series, 6, 100-124. University Press, Cambridge.

The American Water Works Association (AWWA), and the Water Environment Federation (WEF), (2012). Standard Methods of the American Public Health Association (APHA). 